\title{
O DISCURSO DOCENTE ACERCA DO ENSINO DE SOCIOLOGIA E A IDENTIFICAÇÃO IDEOLÓGICA COM O ATUAL PROJETO DE SOCIEDADE
}

\author{
THE DISCOURSE OF TEACHERS ABOUT THE TEACHING OF SOCIOLOGY AND THE IDEOLOGICAL \\ IDENTIFICATION WITH THE CURRENT PROJECT OF SOCIETY
}

\section{EL DISCURSO DE LOS MAESTROS SOBRE LA ENSEÑANZA DE LA SOCIOLOGÍA Y LA IDENTIFICACIÓN IDEOLÓGICA CON EL PROYECTO DE LA SOCIEDAD PRESENTE}

MELO, Valci ${ }^{1}$

\section{RESUMO}

O artigo analisa o discurso de professores de Sociologia acerca do papel dessa disciplina no Ensino Médio. O estudo se deu a partir da Análise do Discurso pecheuxtiana e fez uso de entrevistas e questionários aplicados com dez professores que lecionam Sociologia no Sertão Alagoano. Ao longo do texto, demonstra-se que, embora concebida pelos docentes como uma disciplina conscientizadora e formadora do pensamento crítico, capaz de promover a apreensão da realidade para além do senso comum e tomada como uma ferramenta de intervenção na realidade social, a Sociologia ensinada articula-se mais com o aperfeiçoamento da ordem social vigente do que com a superação da sociabilidade capitalista.

Palavras-chave: Ensino de Sociologia. Análise do Discurso. Ensino Médio. Projeto societário. Emancipação humana.

\section{ABSTRACT}

This article analyzes the discourse of teachers of Sociology about the role of the said discipline in High School. The study be gave from the pecheuxtiana Discourse Analysis and It done use of interviews and questionnaires carried out with ten teachers of Sociology who labour in the Hinterland of Alagoas. Throughout the text, it is shown that, although designed by teachers as an conscientizing discipline and forming of the critical thinking, able to promote the understanding of reality beyond common sense and taken as an intervention tool in the social reality, the Sociology taught is articuled more to the improvement of social order than with the overcoming the capitalist sociability.

Keywords: Teaching of Sociology. Discourse Analysis. High school. Society project. Human emancipation.

\section{RESUMEN}

El artículo analiza el discurso de maestros de Sociología sobre el papel de la disciplina en la escuela secundaria. El estudio se llevó a cabo a partir del análisis del discurso pecheuxtiana e hizo uso de entrevistas y cuestionarios con diez maestros que enseñan en el interior de Alagoas. A lo largo del texto, se muestra que, aunque entendido por los maestros como una disciplina de formación de la conciencia y la del pensamiento crítico, capaz de promover la comprensión de la realidad más allá del sentido común y tomado como una herramienta de intervención en la realidad social, la enseñanza de la Sociología contribuye más a la simple mejora del actual orden social y menos a la superación de la sociabilidad capitalista.

Palabras clave: Enseñanza de la Sociología. Análisis del Discurso. Escuela secundaria. Proyecto de sociedad. Emancipación humana.

\footnotetext{
${ }^{1}$ Universidade Federal de Alagoas - UFAL - Alagoas - Brasil
} 


\section{INTRODUÇÃO}

O retorno da Sociologia como disciplina obrigatória no currículo do Ensino Médio em todo o território nacional, após anos de intermitência e de lutas por sua reintrodução, representa uma importante conquista para a formação intelectual daqueles que passam pela última etapa da Educação Básica na condição de estudantes.

No entanto, como têm demonstrado os estudos que se dedicaram a examinar as expectativas que recaem sobre o ensino dessa disciplina, são muitos os sentidos atribuídos ao papel da Sociologia no Ensino Médio².

Nosso estudo, por sua vez, à luz do materialismo histórico-dialético e a partir do arcabouço teórico-analítico e procedimental da Análise do Discurso, filiada ao filósofo francês Michel Pêcheux (1938-1983), busca analisar como tais expectativas aparecem junto aos professores que lecionam a disciplina no Sertão Alagoano, bem como, em torno de qual projeto societário seus discursos estão articulados.

Escolhemos o Sertão Alagoano como recorte geográfico por ser uma região ${ }^{3}$ pouco pesquisada academicamente - embora corresponda a um terço do território do estado de Alagoas, com 26 municípios e 40 escolas públicas estaduais que ofertam o Ensino Médio, envolvendo, conforme dados do Censo Escolar de 2014, 17.735 estudantes (14,71\% dos estudantes da rede pública estadual).

Para realizar-se, a pesquisa fez uso de entrevistas semiestruturadas (o que nos possibilitou adequar as questões abordadas à disponibilidade de tempo de cada docente) e aplicação de questionários com dez professores que lecionam a disciplina Sociologia em escolas públicas de Ensino Médio situadas na mesorregião do Sertão Alagoano. Mediante esses instrumentos, buscamos compreender quem são eles (sexo, idade, formação inicial e continuada, vínculo empregatício, experiência profissional, condições de trabalho, etc.), como veem a disciplina e como isso se relaciona com a finalidade do ensino de Sociologia na Educação Básica.

Pensamos ser essa amostra (dez professores) representativa do universo pesquisado tanto por ela corresponder a um quinto $(20 \%)$ do professorado que leciona a disciplina na região do Sertão Alagoano, como também, pelo fato de os professores terem sido selecionados com base nos seguintes critérios: a) docentes que atuam em escolas públicas situadas no Sertão Alagoano com a maior quantidade de professores de Sociologia; b) docentes que atuam em escolas com a maior quantidade de estudantes de Ensino Médio; c) docentes vinculados a escolas de cada uma das três Gerências Regionais de Ensino (GERE) do Sertão Alagoano.

Conforme levantamento realizado por email e via telefone junto as três GERE do Sertão Alagoano, a mesorregião conta com cerca de 50 professores que lecionam a disciplina Sociologia, dos

\footnotetext{
${ }^{2}$ Ver a respeito os estudos de Meucci (2000), Guelfi (2001), Santos (2002), Mota (2003), Sarandy (2004), Moraes (2009).

3 De acordo com o Anuário Estatístico do Estado de Alagoas: ano 2012, o referido estado está divido geograficamente em três mesorregiões (Sertão Alagoano, Agreste Alagoano e Leste Alagoano) e 13 microrregiões (ALAGOAS, 2013).
} 
quais apenas 20 têm vínculo efetivo, e destes, somente dois têm formação específica em Ciências Sociais ${ }^{4}$.

Os professores participantes desse estudo representam bem esse cenário, na medida em que dos dez docentes pesquisados, apenas quatro têm vínculo efetivo, e destes, somente um tem formação na área.

A seguir, apresentamos o resultado da investigação. Por razões éticas acordadas entre nós e os professores pesquisados, mediante assinatura de Termo de Consentimento Livre Esclarecido (TCLE), será omitida ao longo do texto a identidade dos sujeitos e das instituições participantes do estudo.

\section{BREVES NOTAS SOBRE A ANÁLISE DO DISCURSO ENQUANTO TEORIA CRÍTICA DA LINGUAGEM}

Neste trabalho, partimos da premissa de que a linguagem, e como diz Bakhtin, no interior desta, a palavra, se constitui em "fenômeno ideológico por excelência" (2006, p. 34, grifo do autor), em signo a partir do qual o ser "[...] não apenas nele se reflete, mas também se refrata" (2006, p. 45, grifos do autor). Isto é, na esteira do materialismo histórico-dialético, em suas contribuições para os estudos acerca da linguagem, mais especificamente, a partir da Análise do Discurso iniciada pelo filósofo francês Michel Pêcheux (1938-1983), entendemos que a língua é portadora de uma autonomia relativa frente à estrutura social e às lutas de classes. No entanto, essa relativa autonomia não a torna imune às contradições, equívocos e falhas que perpassam as relações e os conflitos sociais.

Conforme Pêcheux (1995, p. 91), a língua serve de base, de materialidade para a produção de "efeitos de sentidos" (discurso). Esses "efeitos de sentidos", por sua vez, situam-se no interior de relações ideológicas de classes, fazendo com que, ao enunciar, o sujeito do discurso o faça de um lugar social historicamente determinado com o qual se identifica (formação discursiva) e que, em última instância, define o sentido daquilo que de lá se enuncia (PÊCHEUX, 1995, p. 160-161; PÊCHEUX; FUCHS, 1997, p. 169).

Esse condicionamento histórico-social do dizer, operado pela formação discursiva de onde se enuncia, se dá mediante o papel prático-operativo da ideologia, entendida aqui, na esteira de Lukács (1981, p. 446 apud VAISMAN, 1989, p. 418), como "[...] forma de elaboração ideal da realidade que serve para tornar a práxis social dos homens consciente e operativa".

Assim, de acordo com Vaisman (1989), para Lukács, a ideologia, enquanto mecanismo de tomada de consciência que orienta a intervenção dos homens em seu próprio mundo, é inseparável do ser social, visto tratar-se do instrumento indispensável ao enfrentamento dos problemas da vida cotidiana. Estes problemas, por sua vez, no âmbito da sociedade de classes, se expressam como

\footnotetext{
${ }^{4}$ Entre os professores efetivos, 13 atuam na 11a GERE, a qual também concentra os 02 professores com habilitação específica em sala de aula.
} 
conflitos de classe, sendo a ideologia, neste caso, "um instrumento ideal através do qual os homens e as classes se engajam nas lutas sociais, em diversos planos e níveis" (VAISMAN, 1989, p. 419).

No entanto, ao se reconhecer o condicionamento histórico-social da linguagem e o seu atravessamento pela ideologia, não se está afirmando a existência de algo mecânico e determinista, pois, uma vez produtor e produto das relações sociais nas quais está inserido, o ser social é um ser histórico que, ao mesmo tempo em que está sujeito aos condicionamentos histórico-sociais, faz-se sujeito junto às condições objetivas e subjetivas que o condicionam (PÊCHEUX, 1995; 2006; SILVA SOBRINHO, 2007; MARX, 2011).

É, pois, a partir do "[...] reconhecimento de que somos sujeitos de uma determinada época, inseridos em uma conjuntura histórica que possui modos de pensar dominantes que afetam o nosso dizer e o modo de compreender o mundo" (SILVA SOBRINHO, 2007, p. 66) que nos lançamos ao desafio de investigar os "efeitos de sentidos" (PÊCHEUX, 1995) produzidos pelos professores do Sertão Alagoano acerca do papel a ser desempenhado pela disciplina Sociologia no Ensino Médio. E nossa opção pela $A D$ como método de análise se dá por compreendermos que ela, ao articular de modo materialista histórico-dialético categorias como sujeito, língua, história, ideologia e discurso, corresponde à nossa pretensão de, como diz Cavalcante (2007, p. 13), acessar o "lugar social de onde falam os sujeitos".

\section{O ENSINO DE SOCIOLOGIA FACE AOS DESAFIOS DO ENSINO MÉDIO BRASILEIRO}

Excluída pela reforma educacional do ministro Gustavo Capanema, em 1942, só recentemente, em 2008, a Sociologia voltou a ser um componente curricular nacionalmente obrigatório no Ensino Médio brasileiro.

Antes disso, porém, desde a década de 1980, ela já vinha compondo a matriz curricular de muitos estados, a exemplo de Alagoas, que ainda no final dos anos 1990 inseriu a Sociologia como disciplina escolar.

Se no primeiro momento em que se tornou disciplina nacionalmente obrigatória (1925-1942), em virtude do contexto socio-histórico e das configurações educacionais da época, a Sociologia fazia parte da formação intelectual daqueles estudantes classistamente convocados aos cargos de comando, desde a sua paulatina reintrodução o cenário é bem diferente. No período anterior à exclusão, a Sociologia era ensinada em dois elitizados ramos do ensino de nível médio5: o curso normal, destinado à formação de professores primários, e o curso secundário, voltado à formação dos profissionais liberais.

Para ter-se uma ideia do nível de elitização desses ramos de Ensino Médio, ao analisar as expectativas de Amaral Fontoura acerca das contribuições de seu livro didático, Programa de

\footnotetext{
${ }^{5}$ Além dos cursos normal e secundário, o Ensino Médio era composto dos cursos agrícola, comercial e industrial. No entanto, até a Lei de Diretrizes e Bases de 1961 (LDB 4.024), apenas os dos dois primeiros ramos davam acesso ao ensino superior (Cury, 1998).
} 
sociologia, para a formação de estudantes capazes de conhecer os problemas sociais do Brasil, Meucci (2000, p. 60, grifo nosso) destaca:

\begin{abstract}
Sabemos, a despeito do entusiasmo de Amaral Fontoura, o conhecimento sociológico saíra das academias de direito mas não chegara nem ao operário, nem ao homem de rua. Devemos apenas lembrar que, no Brasil, em 1939 (portanto, apenas um ano antes da publicação deste livro) haviam 629 estabelecimentos de ensino secundário, dos quais 530 eram particulares. Estes dados revelam, com clareza, que o acesso aos cursos secundários era apenas possível a uma parcela bastante restrita da população.
\end{abstract}

Essa observação de Meucci corrobora a tese de Guelfi (2001, p. 31), segundo a qual "tanto o ensino secundário quanto a Sociologia como disciplina escolar foram acessíveis a um grupo 'seleto': aqueles que pretendiam ingressar nas universidades".

Acontece que a reinserção nacional da Sociologia dá-se em um contexto bastante diferente, seja no tocante aos aspectos socioeconômicos e políticos, seja no que diz respeito à situação educacional do país. Reinserida pela Lei $n^{0}$ 11.684, de 02 de junho de 2008 (BRASIL, 2008), a Sociologia é agora destinada à formação de milhões de estudantes oriundos das diferentes classes sociais, contemplados com a expansão massiva da escolarização, como ilustra a garantia da universalização do Ensino Médio, mediante a aprovação da Emenda Constitucional no 59, de 11 de novembro de 2009, que estabelece a obrigatoriedade da Educação Básica dos quatro aos dezessete anos de idade, bem como, da Lei $n^{\circ} 12.061$, de 27 de outubro de 2009, que trata especificamente destas alterações no âmbito do Ensino Médio.

Nesse novo contexto, o ensino de Sociologia lança-se ao desafio de proporcionar aos jovens estudantes brasileiros conhecimentos teóricos e metodológicos que Ihes possibilitem fazer uma leitura distanciada e desnaturalizadora da realidade social, conforme defendido pelas Orientações Curriculares para o Ensino Médio - Conhecimentos de Sociologia (BRASIL, 2006).

Esse documento legal tem um grande significado e um importante papel na história recente do ensino de Sociologia no Brasil, pois ele não apenas reconhece a legitimidade da luta pela reintrodução nacional da referida disciplina escolar (que aconteceu dois anos após a sua publicação), como também traça diretrizes que, desde então, constituem-se referências incontornáveis ao trabalho pedagógico e curricular com a disciplina, a exemplo da produção dos livros didáticos de Sociologia.

As OCEM-Sociologia alicerçam-se naquilo que Moraes e Guimarães (2010, p. 45, grifos dos autores) chamam de "princípios epistemológicos que caracterizam a pesquisa e o ensino das Ciências Sociais, quais sejam, estranhamento e desnaturalização". Para cumprir essa tarefa e, consequentemente, ajudar a Educação Básica em sua finalidade política de "formar os estudantes para o exercício da cidadania", o ensino de Sociologia é pensado, metodologicamente, a partir da articulação entre temas, teorias e conceitos, e no aspecto curricular, a partir da abordagem de questões que envolvam a contribuição das três áreas das Ciências Sociais, a saber: a Antropologia, a Sociologia e a Ciência Política. 
No tocante aos princípios epistemológicos e metodológicos, as OCEM-Sociologia não apenas os identifica explicitamente, como traça considerações sobre os mesmos. Assim, o documento conceitua, exemplifica e destaca o estranhamento e a desnaturalização da realidade social como "o duplo papel" do conhecimento sociológico no Ensino Médio (BRASIL, 2006, p. 105-107). Do mesmo modo, reconhece e aponta sugestões diretas acerca da organização didático-pedagógica:

[...] pode-se verificar que pelo menos três tipos de recortes são reiterados nas propostas construídas para o ensino de Sociologia no nível médio e encontráveis nos parâmetros curriculares oficiais, nos livros didáticos e mesmo nas escolas. São eles: conceitos, temas e teorias. A tendência é os professores, os livros e as propostas apresentarem esses recortes separadamente quando não optam por trabalhar somente com um deles. $\mathrm{O}$ que se propõe aqui para a reflexão dos professores é que esses recortes podem ser tomados como mutuamente referentes, isto é, rigorosamente seria impossível trabalhar com um recorte sem se referir aos outros. O que é possível fazer é tomar um deles como "centro" e os outros como referenciais. (BRASIL, 2006, p. 116-117, grifo dos autores).

Como se vê, as OCEM-Sociologia assumem explicitamente a abordagem didático-pedagógica a partir de conceitos, teorias e temas como recortes metodológicos não apenas já praticados, como também sugerem o seu aperfeiçoamento, mediante a tomada de um dos recortes como elemento central e de sua imprescindível articulação com as outras formas de abordagem dos fenômenos sociais. Mais adiante, o documento procede à conceituação e exemplificação de como seria o trabalho de articulação com cada um dos recortes metodológicos sugeridos.

Já no que se refere ao aspecto curricular, não encontramos nas OCEM-Sociologia o mesmo detalhamento aplicado aos princípios epistemológicos e metodológicos. Isso é justificado pelos autores em face da existência de um trabalho com o ensino de Sociologia em vários estados federativos, materializado em propostas curriculares, livros didáticos e planos de ensino, não havendo, pois, um consenso acerca de um currículo mínimo. Como se tratava de um documento voltado à agregação de forças em prol da reintrodução nacional do ensino de Sociologia, focar em questões sobre as quais já existia um consenso parecia politicamente mais estratégico.

Dois anos após a aprovação da Lei $n^{0} 11.684 / 2008$ (que garantiu a reintrodução do ensino de Sociologia, juntamente com a Filosofia), um dos autores das OCEM-Sociologia, o professor Amaury Cesar Moraes, coordenou junto ao Ministério da Educação (MEC), no âmbito da Coleção Explorando o Ensino, a publicação do documento Sociologia. Dividido em duas partes, esse documento tratou de apresentar, na primeira parte, dois capítulos sobre a história do ensino de Sociologia no Brasil e acerca dos princípios epistemológicos e metodológicos apontados pelas OCEM-Sociologia ${ }^{6}$ e, na segunda

\footnotetext{
${ }^{6}$ Os autores dos capítulos da primeira parte foram: lleizi Luciana Fiorelli Silva, que tinha atuado como leitora crítica das OCEM-Sociologia e agora escreveu sobre o histórico e as perspectivas da disciplina no Brasil, e Amaury Cesar Moraes e Elisabeth da Fonseca Guimarães, que foram consultores e autores do documento de 2006 e agora fizeram uma releitura do mesmo no tocante aos aspectos metodológicos.
} 
parte, apresentou doze capítulos versando sobre cada um dos temas considerados básicos das Ciências Sociais?

Com essas duas publicações do MEC mais a inserção da Sociologia no Programa Nacional do Livro Didático (PNLD) de 2012, garantiu-se, a nível nacional, bem antes da Base Nacional Comum Curricular $\left(\mathrm{BNCC}^{8}\right)$, um conjunto de orientações metodológicas e curriculares acerca do ensino da referida disciplina. Mesmo que essas orientações, diferentemente do que foi definido pela BNCC, não tenha caráter normativo e, portanto, obrigatório, são elas que vêm ajudando a traçar o histórico recente do ensino de Sociologia no Brasil.

Por outro lado, não podemos esquecer que os problemas históricos da etapa educacional em que a Sociologia está inserida interferem diretamente não apenas na qualidade científica e pedagógica da disciplina, como também em sua condição de componente curricular.

O Ensino Médio brasileiro é marcado por uma trajetória de indefinição acerca de sua identidade. Ora ele inclina-se para a formação geral, assumindo, mesmo que formalmente, como no texto da Lei de Diretrizes e Bases da Eduação - LDB 9.394/96, a condição de última etapa da Educação Básica. Em outros momentos ele pende para o lado da preparação imediata de mão de obra para o mercado de trabalho, como se vê na famigerada Reforma do Ensino Médio, materializada na Lei n. 13.415 , de 16 de fevereiro de 2017.

No interior dessas disputas estão os componentes curriculares, a exemplo da Sociologia. Isto é, em um modelo de Ensino Médio pensado como formação ampla e humanística, a Sociologia tem um importante papel científico e pedagógico a desempenhar, pois é uma das disciplinas que ajudam o estudante a pensar criticamente. Contudo, em um formato que preze pelo treinamento e pela formação de mão de obra, disciplinas como a Sociologia e a Filosofia são vistas como desinteressantes e enfadonhas - direção na qual vem sinalizando a BNCC do Ensino Médio, em sintonia com a reforma acima aludida. E isso, como já observara Moraes (2011), tem mais a ver com uma perspectiva tecnocrática de currículo do que com a crença em um suposto potencial subversivo dessas disciplinas escolares.

No tocante à qualidade científica e pedagógica do ensino de Sociologia, cabe observar que diversos elementos que desafiam o Ensino Médio9 ${ }^{9}$ impactam diretamente na referida disciplina. Por não ser esse o nosso objeto de estudo, limitar-nos-emos a tratar brevemente apenas sobre a precarização do trabalho dos professores, tendo em vista que, as condições de formação, trabalho e

\footnotetext{
${ }^{7}$ A segunda parte, escrita por 17 especialistas, versava sobre os seguintes temas: Juventude; Trabalho; Violência; Religião; Diferença e desigualdade; Tecnologia da Informação e Comunicação (TIC); Cultura e alteridade; Família e parentesco; Grupos étnicos e etnicidades; Democracia, cidadania e justiça; Partidos, eleições e governo; e O Brasil no sistema internacional.

${ }^{8}$ Documento oficial elaborado por especialistas nas diversas áreas do conhecimento, sob a coordenação do MEC e com a participação da sociedade, e que estabelece as aprendizagens consideradas "essenciais" para a Educação Básica brasileira.

${ }^{9} \mathrm{O}$ leitor interessado pode consultar, entre outros, os trabalhos de: Frigotto e Ciavatta (2011); Pinto, Amaral e Castro (2011); Machado Costa (2013) e Melo (2017).
} 
carreira docente, conforme observam Kuenzer (2011) e Machado Costa (2013), também se constituem aspectos que desafiam o Ensino Médio.

A escolha desse ponto tem a ver tanto com as exigências epistemológicas, metodológicas e curriculares do ensino de Sociologia, como também, com o perfil do professorado participante desse estudo. Isto é, a lida didático-pedagógica com as Ciências Sociais nos moldes sugeridos pelas OCEMSociologia exige do professorado formação específica e adequadas condições de trabalho.

No entanto, embora os dados estatísticos do Instituto Nacional de Estudos e Pesquisas Educacionais Anísio Teixeira (Inep) de 2015, ano em que realizamos a pesquisa junto aos professores desse estudo, informem que $93,1 \%$ dos professores que atuavam no Ensino Médio tinham formação superior (INEP, 2015a) ${ }^{10}$, quando observada a compatibilidade da formação com a disciplina ensinada, verifica-se que somente $52,6 \%$ deles lecionavam disciplinas para as quais tinham formação em licenciatura ou bacharelado com complementação pedagógica (INEP, 2015b) ${ }^{11}$.

No caso dos professores participantes desse estudo, embora $100 \%$ deles sejam licenciados, apenas $10 \%$ têm formação específica para lidar com o ensino de Sociologia ( $80 \%$ deles têm formação em Pedagogia).

Acerca das condições de trabalho dos professores, os próprios dados oficiais demonstram um elevado processo de precarização. Isso se expressa na excessiva quantidade de estudantes por turma ${ }^{12}$, na larga jornada de trabalho, uma vez que $43,3 \%$ dos docentes do Ensino Médio têm entre 50 e 400 alunos e atuam em dois turnos e em mais de uma escola (INEP, 2015c); e na desvalorização social e salarial, na medida em que a média salarial dos docentes em regime de 40 horas semanais da rede pública estadual corresponde a apenas $45 \%$ da remuneração do professorado que atua na rede pública federal de ensino com a mesma escolaridade (INEP, 2014).

No caso dos professores participantes desse estudo, as condições de trabalho e carreira docente são piores que a média nacional exposta acima. Eles atuam em turmas com média de 40 estudantes, atendem entre 50 e 700 alunos e $90 \%$ deles atuam em dois ou mais turnos e em duas ou mais escolas. Quanto à remuneração, a maioria dos professores pesquisados (60\%) tem vínculo de monitoria, recebendo 15 reais por hora-aula.

É, pois, sob essas condições que se dá o trabalho didático-pedagógico dos professores de Sociologia do Sertão Alagoano, cujo discurso docente será analisado a seguir.

Para diferenciar as Sequências Discursivas (SD) resultantes das entrevistas com os professores das citações diretas longas, identificamos as primeiras colocando a sigla SD entre colchetes, acompanhada de um algarismo arábico em ordem crescente.

\footnotetext{
${ }^{10}$ Os últimos dados, correspondentes ao ano de 2017, indicam que esse percentual ainda está em 93,8\%. Dados disponíveis em: http://portal.inep.gov.br/indicadores-educacionais. Acesso em 23 set. 2017.

${ }^{11} \mathrm{Em} 2017$ esse dado subiu para 54,9\%.

12 A média nacional era 30,2 estudantes por turma em 2015. Em 2017 essa média subiu para 30,4. Dados disponíveis em: http://portal.inep.gov.br/indicadores-educacionais. Acesso em: 23 set. 2017.
} 


\section{O ENSINO DE SOCIOLOGIA SOB A ÓTICA DOS PROFESSORES}

\section{A Sociologia como disciplina conscientizadora e formadora do pensamento crítico}

Questionados sobre o que pensam acerca do ensino de Sociologia, os professores são unânimes em reconhecer a importância da disciplina, justificando a presença desta no Ensino Médio, como é possível ver nas sequências discursivas (SD) abaixo, pela capacidade que a mesma teria de promover uma elevação da consciência social e política dos estudantes acerca da realidade na qual vivem.

[SD1] É uma disciplina interessante, pois envolve o humano e o social ao mesmo tempo, podendo resgatar a cidadania que está oculta nas pessoas (PROFESSOR/A RG, grifos nossos).

[SD2] A Sociologia orienta os nossos educandos a compreender seu espaço e atuação na sociedade (PROFESSOR/A AE, grifos nossos).

[SD3] É de fundamental importância. Esta área do conhecimento é um dos principais meios de conscientização do nosso alunado de que somos cidadãos. Vivemos em um meio social onde temos direitos $e$ deveres a cumprir. Só assim poderemos fazer valer o sistema que denominamos "democracia" (PROFESSOR/A AMA, grifos nossos).

[SD4] É fundamental para a formação dos alunos visto que os conteúdos trabalhados contribuem para que estes possam exercitar o pensamento crítico em relação a realidade a que pertencem (PROFESSOR/A AS, grifos nossos).

Conforme se vê nos enunciados acima, a disciplina Sociologia aparece justificada face à importância e necessidade desta para resgatar a cidadania (SD1), orientar os estudantes na compreensão de seu espaço e atuação na sociedade (SD2), conscientizar o alunado (SD3) e auxiliar os discentes no exercício do pensamento crítico (SD4). Todas essas questões, de um modo geral, revelam a preocupação dos docentes com uma dimensão politizadora da disciplina, a qual, ao lidar 
diretamente com a reflexão sociológica dos problemas sociais, busca ir além da compreensão teórica da realidade que toma como objeto de análise.

Essa expectativa de que o ensino de Sociologia seja "conscientizador" e "crítico" não é algo que se limite ao contexto geográfico investigado, uma vez que discursos nessa direção aparecem também nos estudos de Santos (2002), Mota (2003), Eras (2006) e Lima (2012) - para citar apenas aqueles que trataram diretamente, no todo ou em algum momento de seus trabalhos, sobre a concepção dos docentes (e alguns também dos discentes) acerca do ensino de Sociologia.

No caso do estudo de Lima (2012), por exemplo, a autora observa a expectativa dos professores de que o conhecimento sociológico ajude no disciplinamento dos estudantes, na medida em que aborda regras e normas de convivência social, algo que dialoga, a nosso ver, com o discurso materializado na SD2 acerca do papel da Sociologia na orientação dos estudantes sobre o seu espaço e atuação na sociedade.

Assim, entendemos que o discurso materializado nas sequências selecionadas parafraseia ${ }^{13}$ a expectativa acerca do ensino de Sociologia expressa em documentos oficiais como os Parâmetros Curriculares Nacionais para o Ensino Médio (PCNEM), da área de Ciências Humanas e suas Tecnologias, no interir do qual são contemplados os conhecimentos de Sociologia, Antropologia e Ciência Política. De acordo com o referido documento:

[...] pela via do conhecimento sociológico sistematizado, o educando poderá construir uma postura mais reflexiva e crítica diante da complexidade do mundo moderno. Ao compreender melhor a dinâmica da sociedade em que vive, poderá perceber-se como elemento ativo, dotado de força política e capacidade de transformar e, até mesmo, viabilizar, através do exercício pleno de sua cidadania, mudanças estruturais que apontem para um modelo de sociedade mais justo $e$ solidário. (BRASIL, 1999, p. 37, grifos nossos).

O fragmento acima não esconde o seu alinhamento a uma perspectiva de aperfeiçoamento da ordem social vigente, uma vez que, entre outras questões, ao defender "um modelo de sociedade mais justo e solidário", pressupõe que vivemos em uma sociedade que já é justa e solidária, carecendo somente intensificar tais qualidades (mais = advérbio de intensidade).

Claro que no caso das sequências discursivas SD1 a SD4, se nos prendermos apenas à superfície linguística ${ }^{14}$ faltarão elementos que justifiquem uma identificação completa entre os discursos materializados nelas e aquele corporificado no texto dos PCNEM. Contudo, tanto alguns dos enunciados já deixam pistas nessa direção, a exemplo do que acontece com a SD2, ao pressupor que existe um espaço a ser ocupado pelos estudantes nessa sociedade e que essa ocupação poderá se dar por meio dos conhecimentos proporcionados pelo ensino da Sociologia, como também, outros

\footnotetext{
${ }^{13}$ Segundo Pêcheux (1995, p. 177), o lugar social de onde se fala (formação discursiva) é constituído pela reformulação e pela paráfrase. Isto é, embora o dizer, ao recorrer a uma memória discursiva, retome um jádito, não o faz como simples repetição, mas sim, como ressignificação.

${ }^{14}$ Conforme Orlandi (2007, p. 66), a superfície linguística corresponde ao "corpus bruto", ao "dado empírico de um discurso concreto".
} 
enunciados dos mesmos sujeitos, como veremos mais adiante, esclarecem o horizonte societário dessa cidadania resgatada (SD1), desse espaço a ser ocupado (SD2), da conscientização (SD3) e do pensamento crítico (SD4).

Essa identificação ideológica (PÊCHEUX, 1995) entre o discurso docente e os "efeitos de sentidos" produzidos por documentos oficiais do Estado brasileiro demonstra o papel da memória discursiva enquanto mecanismo de continuidade temática que inscreve o discurso no terreno da História (PÊCHEUX, 1999, p.56; 2006, p. 56). Isso porque, embora retome um já-dito nos PCNEM, curiosamente, nenhum dos docentes destacou esse documento entre aqueles que já leu e/ou utiliza como referência para lidar com a disciplina. Contudo, graças ao papel da memória discursiva ${ }^{15}$, tal fato não impede que seus discursos sobre a dimensão conscientizadora da Sociologia se articule com aquilo que é defendido pelo referido documento, em um movimento de reformulação-paráfrase (PÊCHEUX, 1995).

A lista acerca dos documentos oficiais apresentada aos professores continha as seguintes opções: 1) Lei de Diretrizes e Bases da Educação - LDB 9.394/96; 2) Diretrizes Curriculares Nacionais para o Ensino Médio - DCNEM de 1998; 3) Diretrizes Curriculares Nacionais para o Ensino Médio DCNEM de 2012; 4) Orientações Curriculares para o Ensino Médio - OCEM-Sociologia; 5) Parecer CNE/CEB n. ${ }^{\circ} 38 / 2006$; 6) Referencial Curricular da Educação Básica para as Escolas Públicas de Alagoas (RECEB-AL); 7) Nenhum e 8) Outro, solicitando, neste último caso, a especificação do texto.

Entre os documentos mais conhecidos pelos docentes, destacaram-se a LDB 9.394/96, as DCNEM de 1998 e de 2012 e o RECEB-AL. Contudo, como já enfatizado, pensamos que a falta de leitura de alguns documentos (mesmo se tratando daqueles mais específicos da área) não significa dizer que os professores não considerem, na lida com a disciplina, aspectos que os coloca em identificação ideológica com os mesmos, uma vez que há um núcleo comum entre os diversos documentos que, de certa forma, os aproximam naquilo que nos parece essencial, que é o projeto de sociedade em torno do qual estão articulados.

Ainda nesse particular, temos que considerar o papel sintetizador e disseminador do livro didático, que tem como um dos critérios de avaliação o respeito à legislação vigente, inserindo-se aí a maioria desses documentos: LDB 9.394/96, as DCNEM e, como demonstra o Guia de livros didáticos (BRASIL 2011), é forte a consideração das OCEM-Sociologia nos livros selecionados.

Também se observa que o discurso materializado nas SD1 a SD4 identifica-se com a ideia bastante frequente acerca do ensino de Sociologia que diz respeito a uma suposta dimensão eminentemente crítica dessa disciplina, a qual, independentemente das condições e do modo como é ensinada, parece promover o real conhecimento da vida social. Nessa lógica, a Sociologia, inevitavelmente, incomodaria a ordem estabelecida, sendo, pois, esse o motivo responsável por sua exclusão do currículo escolar em outros momentos e a razão de ela continuar ameaçada de banimento na contemporaneidade. Não entraremos aqui no mérito da discussão, mas ao leitor interessado, vale a

\footnotetext{
${ }^{15}$ De acordo com Florêncio et al. (2009, p. 79), a memória discursiva corresponde ao lugar onde se encontra o interdiscurso (o já-dito) que é retomado pelo dizer atual (interdiscurso).
} 
pena conferir a crítica a esse discurso rascunhada nas OCEM-Sociologia (BRASIL, 2006), bem como, melhor desenvolvida em Moraes (2011; 2014) e Oliveira (2013).

\section{A SOCIOLOGIA COMO APREENSÃO DA REALIDADE PARA ALÉM DO SENSO COMUM}

Além de conscientizadora e formadora do pensamento crítico, a disciplina Sociologia é concebida pelos professores pesquisados como geradora de um tipo de conhecimento acerca da realidade social que extrapola a simplificação do senso comum, a superficialidade das aparências.

[SD5] [...] O cidadão... Ele é muito bitolado na questão de aceitar tudo. Certo? Sem ter a liberdade de expressão, sem ter uma consciência até às vezes do que ele está agindo... Eu acho que a Sociologia em si ela leva você a pensar, a ver as coisas de uma forma..., uma visão de mundo mais diferente da que a gente imagina (PROFESSOR/A MG, grifo nosso).

[SD6] [...] A Sociologia não trabalha nada mais do que o que a gente convive no dia a dia. A questão é que com a visão mais apurada, mais trabalhada, mais técnica, mais científica. É no sentido de aprofundar essas explicações que a gente já tem. [...] Então, eu digo a eles que a importância de estudar Sociologia é nesse sentido: da gente ter uma visão mais apurada, um conhecimento mais aprofundado das causas, das consequências, dos motivos do que acontece na sociedade (PROFESSOR/A AM, grifos nossos).

[SD7] [...] Costumo dizer que a Sociologia ela é uma disciplina extremamente importante pra sociedade em si. Pra quê Sociologia? Fazer com que cada aluno se torne um cientista social, se torne uma pessoa da qual irá analisar a sociedade e, a partir dessa análise, poder também atuar dentro dos seus limites, das leis, etc. [...] Atuar como agente participante que irá participar, que irá conduzir, que irá está à disposição da sociedade para melhorá-la. Esse é o sentido principal (PROFESSOR/A RF, grifo nosso).

[SD8] Proporcionar a reflexão sobre os assuntos que estão ao nosso redor, que os alunos sejam capazes de ver além das aparências e despertem o interesse em participar de assuntos comuns a nossa sociedade como participação política, reivindicações, direitos e deveres, etc. (PROFESSOR/A AS, grifo nosso). 
Não há dúvida de que o conhecimento das Ciências Sociais precisa ir além do senso comum, caso contrário, não se justificaria enquanto conhecimento científico. No entanto, entre ir além do senso comum e desenvolver uma leitura que consiga, de fato, capturar a essência da realidade social (ir além das aparências) existe uma diferença com a qual nem sempre a própria ciência sociológica tem se preocupado, sobretudo, em tempos pós-modernos nos quais, como observam Paulo Netto (2010) e Tonet (2013), afirma-se a impossibilidade de se alcançar a raiz dos fenômenos sociais.

De acordo com o discurso materializado nos enunciados anteriores, o conhecimento das Ciências Sociais diferencia-se daquele a que os estudantes têm acesso no cotidiano por instigá-los ao pensamento (SD5), ao conhecimento das causas e consequências (SD6), por auxiliá-los a ver além das aparências (SD8) e, assim, fazer com que os educandos analisem a sociedade como cientistas sociais (SD7), isto é, amparados em um tipo de conhecimento que tem a autoridade e o respaldo da ciência.

Nada haveria a objetar se o conhecimento produzido pelas Ciências Sociais, e didatizado no âmbito do Ensino Médio pelos docentes pesquisados, não estivesse tão mais articulado com o aperfeiçoamento da ordem social vigente do que com a real superação da sociedade de classes, em especial, a capitalista. Isso, por sua vez, se não impossibilita a superação do senso comum no trato de muitos dos temas abordados pelos docentes, o mesmo não se pode dizer acerca do conhecimento das causas dos problemas sociais e da própria elevação do senso comum na abordagem de questões como desigualdades, pobreza, estratificação, classes sociais, política, Estado, etc., uma vez que, para tal, é preciso ir além, tanto das aparências cotidianas, como também, da frequente superficialidade acadêmica que, ao tomar essas problemáticas como dadas, limita-se a pensar em como administrá-las.

Chama a atenção ainda, no discurso materializado na SD5, a caracterização do cidadão como um ser bitolado, controlado, mas que, nem por isso, deixa de ser cidadão. A bitola corresponde a uma medida que calcula a distância exata entre os trilhos nas linhas férreas, entre as ripas na cobertura de telhados, etc. Assim, a bitola serve para evitar que os objetos controlados saiam da linha, desviem-se do percurso esperado. Mesmo assim, como se vê na SD5, é possível ser cidadão sem deixar de ser bitolado, uma vez que a cidadania, conforme observa Tonet (2007), limita-se a um conjunto de direitos e deveres que, apesar de sua importância e das tensões sob as quais sobrevive, consegue conviver com a exploração do homem contra o próprio homem.

Já sobre ser competência do Ensino Médio, por meio da disciplina Sociologia, fazer com que o estudante se comporte como um cientista da área na análise da vida social (SD7), penso que talvez se trate de uma expectativa um pouco exagerada, tanto pelas condições sobre as quais se dá o ensino de Sociologia, como também porque compete ao Ensino Superior desenvolver esse tipo de habilidade, cabendo ao Ensino Médio iniciar os educandos nas Ciências Sociais e tratar daquilo que se constitui conhecimento geral e básico da área, como acontece com os demais componentes curriculares.

Ainda de acordo com os professores, o conhecimento das Ciências Sociais no Ensino Médio justifica-se também por possibilitar aos estudantes um tipo de leitura acerca da realidade social que vai 
além daquilo que é comumente praticado no dia a dia, especialmente, sob a influência da mídia televisiva que, conforme alerta um/a dos/as professores/as:

[SD9] [...] Eu digo para os meus alunos: olhe, a gente tem que ter uma visão crítica do que a gente assiste na televisão, seja a novela, seja o filme, seja a propaganda... Geralmente eu uso muita propaganda pra dar exemplo a eles de como a mídia ela sempre tenta passar pra gente uma ideologia, uma mentira, muitas vezes, que ela é dita de uma forma tão bela que a gente passa a acreditar que aquilo é verdade. E aí como é que eu (um jovem, mãe, pai) posso ter uma mudança? Depende desse olhar crítico, seja na música que eu ouço, seja nos programas que eu assisto (PROFESSOR/A KA, grifos nossos).

O discurso materializado no enunciado acima também retoma a crença bastante difundida academicamente, e entre os docentes da área, acerca da dimensão crítica da Sociologia, a qual seria capaz de auxiliar os estudantes no desvelamento daquilo que chega até eles como verdade, sobretudo, através dos meios de comunicação de massa. Neste sentido, ao fornecer um tipo de conhecimento que extrapola o senso comum, a Sociologia ensinada na última etapa da Educação Básica supostamente contribuiria para a desnaturalização da realidade social que, conforme as OCEM-Sociologia, consiste em um dos papeis da disciplina (BRASIL, 2006, p.105-106). E, como se vê na sequência discursiva abaixo (e caracteriza-se como um discurso comum entre os professores entrevistados), essa desnaturalização tem como foco o despertar dos estudantes para a prática, para a mudança de comportamento (conscientização) frente aos problemas sociais, para a intervenção na realidade social.

[SD10] [...] Nós temos indivíduos que estão concluindo o Ensino Médio [...] vão se tornar trabalhadores, vão se tornar as pessoas que irá (sic) conduzir a sociedade em um ciclo (e isso é normal), o mínimo que tem que ser feito é fazer com que essas pessoas compreendam o seu papel dentro da sociedade. E que possa participar e não ser só um indivíduo do qual..., uma massa de manobra. Porque se a gente analisar as decisões sociais, elas acontecem, se você analisar sociologicamente dentro da ciência, você vai entender que há uma série de pessoas favorecidas sobre determinado fato, sobre determinado acontecimento. E quem não tem uma aproximação maior com a ciência da Sociologia, com a disciplina etc., costuma achar que isso é um acontecimento natural porque isso tem que ser assim etc., quando a gente sabe que inúmeras decisões, inúmeras questões que afetam principalmente a maioria das pessoas elas são tomadas por um pequeno grupo da sociedade. E esse pequeno grupo... Aí neste sentido você precisa 
entender o seu papel de cidadão; cidadão participativo (PROFESSOR/A RF, grifos nossos).

Ora, nada haveria a objetar se esse processo de desnaturalização não fosse seletivo, isto é, usado para algumas questões e totalmente esquecido no trato de outras. Ou seja, a maioria dos professores que reivindica a contribuição da Sociologia no reconhecimento da historicidade da vida social, que destaca o papel da disciplina na formação do pensamento crítico, esquece esta historicidade e a necessidade de ir além das aparências quando é posto em discussão algo que transcenda o simples aperfeiçoamento da ordem social vigente. E esse esquecimento, por sua vez, não é acidente de percurso, e sim, efeito ideológico da formação discursiva dominante com a qual o sujeito-falante ${ }^{16}$ se identifica e de onde enuncia. Neste sentido, como observa Pêcheux (1995, p.183, nota 32), o esquecimento não significa lapso de memória acerca de algo que um dia se soube, e sim, o acobertamento dos fundamentos, das causas e do condicionamento socio-histórico do próprio sujeitofalante ${ }^{17}$.

\section{A SOCIOLOGIA COMO FERRAMENTA DE INTERVENÇÃO NA REALIDADE SOCIAL}

Há entre alguns dos professores pesquisados a compreensão de que é papel da Sociologia desvelar o funcionamento da vida em sociedade em todas as suas dimensões, ajudando os estudantes a compreender o processo de socialização e das relações sociais (SD11), bem como, abrindo novos horizontes explicativos acerca da vida cotidiana (SD12).

[SD11] Como a gente vive no meio social (nós não vivemos isolados), a gente precisa compreender como acontece essa convivência diária. [...] A gente precisa refletir e compreender como se dá essa relação entre as pessoas. [...] E a Sociologia é uma disciplina que leva a isso (PROFESSOR/A AMA, grifo nosso).

[SD12] [...] A disciplina propõe a descoberta de novos horizontes que possibilitam a aprendizagem entre os processos históricos sociais e a vida cotidiana, como aquela que molda e transforma o pensamento leigo dos alunos para novas descobertas (PROFESSOR/A DS, grifos nossos).

\footnotetext{
${ }^{16} \mathrm{Na}$ esteira de Pêcheux (1995), ao enunciar, o sujeito do discurso o faz afetado pela ideologia que controla a formação discursiva de onde ele enuncia. No entanto, não sendo essa sua relação com o "sempre-já-assim" mecanicamente determinada, abre-se espaço para ir-se além da retomada e incorporação de sentidos, fazendo-se uso da língua para também deslocar sentidos, produzindo-se o novo. Daí ser ele um ser condicionado, mas também, um sujeito de sua história.

${ }^{17}$ Sobre o esquecimento, ver Pêcheux (1995, p.173).
} 
No entanto, além disso, o discurso dos professores revela uma concepção de que, aliado ao conhecimento das Ciências Sociais acerca da realidade em que vivem os estudantes, deve está o posicionamento (SD13) e o engajamento político destes no sentido de tornar essa sociedade (não se trata de construir outra) "mais justa e fraterna" (SD14).

[SD13] [...] Eu costumo sempre repetir o objetivo da Sociologia nas minhas aulas. Sabe, eu costumo sempre dizer que é o objetivo da gente analisar os problemas da sociedade. É tentar compreendê-los e compreender também a nossa postura diante desses problemas. [...] Qual a nossa postura diante desses problemas sociais? (PROFESSORA LF, grifo nosso).

[SD14] Incentivar essa juventude para um despertar, contribuindo para uma sociedade mais justa e fraterna onde eles possam questionar, criticar e tentar compreender (PROFESSOR/ RG, grifos nossos).

Essa intervenção, conforme aponta a maioria dos professores, tem o exercício da cidadania não apenas como meio, mas também como horizonte. E, no caso do Sertão Alagoano, embora o percentual de professores com licenciatura específica que investigamos seja pequeno em relação à própria amostra da pesquisa, não visualizamos, no que tange a essa questão, uma diferenciação entre o professor licenciado e os docentes sem formação na área. Claro que, como já salientamos, o percentual é pequeno e isso também não nos autoriza a afirmar que eles lidam da mesma forma com a disciplina. $\mathrm{O}$ que queremos aqui é assinalar que, no que se refere à maneira como pensam a finalidade da disciplina, eles não se diferenciam, como aconteceu com os sujeitos pesquisados por Santos (2002). Isto é, em sua pesquisa sobre as representações sociais dos professores do Distrito Federal, o autor observou que, apesar de ser comum entre os docentes a vinculação ensino de Sociologia e exercício da cidadania, somente aqueles com formação em outras áreas do conhecimento, e não em Ciências Sociais, apresentavam a expectativa de que o ensino dessa disciplina conscientize os estudantes e, consequentemente, instrumentalize-os para os desafios imediatos do cotidiano.

Ainda neste aspecto, é importante destacar que a identificação entre os discursos dos professores vai além do quesito formação, não existindo qualquer diferença substancial quando observadas também variáveis como tempo de magistério, tempo lecionando a disciplina Sociologia, vínculo empregatício ou condições de trabalho. Isto é, embora o grupo pesquisado seja heterogêneo em muitas dessas questões, seus discursos dialogam e identificam-se ideologicamente.

Outra questão importante a se destacar acerca dessa relação entre o conhecimento das Ciências Sociais e a intervenção na realidade social é que, ao mesmo tempo em que os professores pesquisados parecem compreender que não se trata de uma relação direta (daí o uso de verbos que 
indicam apenas possibilidade, como: "tentar", "contribuir", etc.), acreditam que, caso ela se materialize, teremos como resultado uma sociedade melhor. Esse discurso, por sua vez, acaba silenciando ${ }^{18}$ acerca da existência de uma sociedade fragmentada em classes sociais com interesses antagônicos, no interior da qual não há possibilidade de um conhecimento neutro que vise automaticamente o bem comum.

Analisando essa relação entre conhecimento das Ciências Sociais e intervenção na realidade social, Santos (2002, p. 125, grifos do autor), observa:

\begin{abstract}
Nessa perspectiva, na escola, o instrumental sociológico permite ao educando entender que diante dos fatos sociais, ele pode fazer leituras diferentes daquela que faria baseado no senso comum. Contudo, agir em um sentido ou em outro; ou mesmo não agir é uma opção do indivíduo. A Sociologia apenas contribui para que os alunos ampliem a compreensão acerca da realidade social, consequentemente "na medida, em que eles conhecem isto, eles têm o poder de optar". (SANTOS, 2002, p.125, grifo do autor).
\end{abstract}

Como ressalta o autor acima mencionado, cabe em última instância ao estudante materializar essa relação entre conhecimento das Ciências Sociais e intervenção na realidade social. No entanto, pensamos ser necessário destacar que essa autonomia estudantil, tão defendida por Moraes (2014), é bastante relativa, visto que o conhecimento das Ciências Sociais oportunizado aos estudantes passa, antes, pelo crivo daquilo que, no mínimo, os estados (a partir de suas diretrizes curriculares ${ }^{19}$ ), o livro didático e o professor (a partir da seleção, organização e abordagem dos conteúdos) definem como "coisas a saber" (PÊCHEUX, 2006). E isso, por sua vez, pode facilitar ou dificultar tanto a elevação do conhecimento acerca da realidade social, como também a decisão dos estudantes de colocarem este conhecimento em prática - e em qual direção societária.

\title{
CONSIDERAÇÕES FINAIS
}

Neste trabalho, buscamos analisar os "efeitos de sentidos" (PÊCHEUX, 1995) produzidos pelos professores do Sertão Alagoano ao versarem sobre o ensino da disciplina Sociologia, bem como, identificar em torno de qual projeto societário seus discursos estão articulados.

Ao longo do estudo, mostramos que, embora concebida pelos docentes como uma disciplina conscientizadora e formadora do pensamento crítico, capaz de promover a apreensão da realidade para além do senso comum e tomada como uma ferramenta de intervenção na realidade social, a Sociologia ensinada no Sertão Alagoano não tem como horizonte societário algo que transcenda a emancipação política, isto é, um conjunto de conquistas que possibilite aos indivíduos vivenciarem

\footnotetext{
${ }^{18}$ Conforme Orlandi (1995, p. 75-76), ao se dizer algo se interdita outros dizeres e sentidos possíveis, os quais são silenciados por serem indesejáveis em uma dada situação discursiva.

${ }^{19}$ Conforme Caridá (2014, p.23), 14 estados da federação já contam com diretrizes curriculares voltadas ao ensino de Sociologia, sendo a maior defasagem nas regiões Norte e Nordeste que juntas têm apenas 04 estados com as diretrizes elaboradas. As regiões Sul e Sudeste têm diretrizes em todos os estados e no CentroOeste apenas o estado de Mato Grosso do Sul ainda não tinha elaborado o documento.
} 
alguns direitos e deveres (cidadania) e participarem, sobretudo, por meio de representantes eleitos (democracia), das decisões que afetam a coletividade.

Essa forma de emancipação (a emancipação política), como observa Marx (2010a, p. 41) no texto Sobre a questão judaica é, inegavelmente, uma conquista social que torna melhor as condições de vida e de luta dos trabalhadores. Contudo, apesar do progresso civil, político e social possibilitado por ela, trata-se de uma emancipação formal, jurídico-política e, portanto, incapaz de superar as contradições e os limites estruturais da sociedade de classes.

Já a emancipação humana, para Marx, constitui a emancipação real, prática, a forma de sociabilidade na qual os seres humanos exerceriam coletivamente - e de modo consciente -, a partir das condições objetivas e subjetivas favoráveis, a direção da própria história. Isto é, diz respeito a um processo contínuo no qual seria possível ao ser social vivenciar, a partir da "[...] restituição do mundo e das relações humanas aos próprios seres humanos" (IASI, 2011, p. 56), o "reino da liberdade", sem que esse valor se confronte, como é o caso da emancipação política, com o valor da igualdade, que se dá apenas de modo abstrato e formal.

Pelo exposto, vê-se que a emancipação humana não pode ser resultado da mera vontade dos indivíduos, nem da simples ocupação do poder Estatal. Conforme Marx (2010b, p. 78), ela deve ser resultado de uma "revolução política com alma social", isto é, de uma revolução que não somente ocupe o Estado, mas que também o destrua enquanto órgão de classe, juntamente com o aniquilamento da propriedade privada, das classes sociais e, portanto, da exploração do homem sobre o próprio homem.

Diante desse cenário, qual seria, pois, o papel da educação e, mais especificamente, da escolarização? Existe mesmo alguma possibilidade de a escolarização contribuir para a "emancipação de fato", real, prática, e não somente, para a "emancipação de direito", formal?

Acerca dessas questões, pensamos que Mészáros tem razão ao destacar que a resolução de tal problemática encontra-se na árdua tarefa de conciliação dialética entre táticas e estratégias, isto é, entre o horizonte societário (a emancipação humana) e o "[...] projeto de mediações concretas pelas quais a estratégia final pode ser progressivamente traduzida em realidade" (MÉSZÁROS, 2011, p. 597, grifo do autor).

Neste particular, como reconhece o supracitado autor, nem o Estado pode ser ignorado enquanto esfera social de luta, nem a educação, inclusive a escolarização, pode ser desprezada enquanto mecanismo potencial de formação da consciência socialista (MÉSZÁROS, 2008).

Claro que tal consideração não ignora o condicionamento histórico-social da prática educativa e o predomínio da internalização das ideias, dos valores e dos comportamentos favoráveis à classe dominante, uma vez que, conforme nos lembra Tonet (2014, p. 14), as definições acerca do que ensinar (e sob quais condições) se dá no âmbito do Estado.

Contudo, tal processo, embora se dê sob a hegemonia do Estado e, portanto, predominantemente a serviço da classe dominante, não se constitui em um domínio absoluto deste, 
pois em seu interior existe e pulsa a luta de classes. É, pois, esta dimensão contraditória sob a qual se assenta a sociedade de classes, em especial a sociedade capitalista, que permite a existência do que Tonet $(2007 ; 2014)$ denomina "atividades educativas emancipadoras". Ou seja, conforme o autor, tratase daquelas atividades formativas que se articulam, direta ou indiretamente, com a negação da sociedade capitalista enquanto alternativa única e com a defesa da emancipação humana como horizonte societário.

Para que essas atividades se desenvolvam, inclusive no âmbito da escolarização, Tonet (2007, p. $67-69 ; 2014$, p.10) enumera cinco requisitos, a saber: 1) clareza do fim pretendido e de suas necessárias e possíveis mediações; 2) capacidade para analisar a conjuntura e a lógica de funcionamento do processo em curso em suas dimensões micro e macro; 3) apropriação dos elementos essenciais que dizem respeito à natureza e à função social da prática educativa; 4) conhecimento profundo acerca do objeto/área de atuação; 5) habilidade para articular as práticas localizadas com as lutas mais gerais, sejam estas específicas do campo educacional ou não.

Neste sentido, conforme observa Tonet, diante da impossibilidade de um sistema educacional emancipador sob a ordem social vigente, resta-nos trabalhar com atividades educativas que apontem no sentido da emancipação, ou seja, com atividades que estejam conectadas não com o aperfeiçoamento e a reprodução da sociedade burguesa, mas com a construção de uma sociedade, de fato, livre, justa e igualitária.

Nessa tarefa, ao lidar diretamente com a análise científica da vida social, o ensino de Sociologia carrega consigo possibilidades de contribuição para a emancipação humana, na medida em que pode favorecer a compreensão dos fenômenos sociais e de seus fundamentos e desdobramentos sócio-históricos. No entanto, como nos mostrou o presente estudo, essas possibilidades são limitadas tanto pelo delineamento jurídico-político da disciplina, como também, pela apreensão que os docentes fazem da mesma - isso sem falar nas configurações acadêmicas das Ciências Humanas e Sociais e da Filosofia, as quais, como observa Tonet (2014, p. 17) “[...] são, hoje, cada vez mais hegemonizadas por um viés conservador, quando não reacionário mesmo. As elaborações mais avançadas não vão além de advogar a reforma, o aperfeiçoamento, a humanização do capitalismo".

Assim, concluímos destacando que, embora o ensino de Sociologia possa contribuir para a emancipação humana, da forma como tem se dado, tomando a emancipação política enquanto horizonte societário, e não, como mediação para além de si mesma, está comprometido com o aperfeiçoamento e, portanto, com a manutenção da ordem social vigente.

\section{REFERÊNCIAS}

1. ALAGOAS. Anuário Estatístico do Estado de Alagoas: ano 2012. Maceió: Seplande, 2013.

2. BAKHTIN, Mikhail. Marxismo e filosofia da linguagem. 12. ed. São Paulo: Hucitec, 2006. 
3. BRASIL. Parâmetros Curriculares Nacionais Ensino Médio. Ciências Humanas e suas Tecnologias. Brasília: MEC, 1999. Orientações curriculares para o Ensino Médio. Brasília, DF: MEC, 2006.

Lei $n^{\circ} 11.684$, de 2 de junho de 2008. Altera o art. 36 da lei $n .^{\circ} 9.394$, de 20 de dezembro de 1996, que estabelece as diretrizes e bases da educação nacional, para incluir a Filosofia e a Sociologia como disciplinas obrigatórias nos currículos do ensino médio. Diário Oficial [da] República Federativa do Brasil, Brasília, 3 jun. 2008. Seção 1, p. 1. Emenda constitucional $n^{\circ}$ 59, de 11 de novembro de 2009. Diário Oficial [da] República Federativa do Brasil, Brasília, 12 nov. 2009.

Lei $\mathrm{n}^{\circ}$ 12.061, de 27 de outubro de 2009. Altera o inciso II do art. 4o e o inciso VI do art. 10 da Lei no 9.394, de 20 de dezembro de 1996, para assegurar o acesso de todos os interessados ao ensino médio público. Diário Oficial [da] República Federativa do Brasil, Brasília, 28 nov. 2009. Seção 1, p.1.

Guia de livros didáticos: PNLD 2012. Sociologia. Brasília: Ministério da Educação, Secretaria de Educação Básica, 2011.

9. CARIDÁ, Ana Carolina Bordini Brabo. Sociologia no ensino médio: diretrizes curriculares e trabalho docente. 2014. 145f. Dissertação (Mestrado em Sociologia Política) - Universidade Federal de Santa Catarina, Florianópolis, 2014.

CAVALCANTE, Maria do Socorro Aguiar de Oliveira. Qualidade e cidadania nas reformas da educação brasileira: o simulacro de um discurso modernizador. Maceió: Edufal, 2007.

11. CURY, Carlos Roberto Jamil. O ensino médio no Brasil: histórico e perspectivas. Educação Em Revista, Belo Horizonte, n. 27, jul. 1998.

ERAS, Lígia Wilhelms. O trabalho docente e a discursividade da autopercepção dos professores de sociologia e filosofia no ensino médio em Toledo/PR. 2006. 277 f. Dissertação (Mestrado em Letras) - Universidade Estadual do Oeste do Paraná, Paraná, 2006.

13. FLORÊNCIO, Ana Maria Gama et. al. Análise do discurso: fundamentos e prática. Maceió: EDUFAL, 2009. 
14. FRIGOTTO, Gaudêncio; CIAVATTA, Maria. Perspectivas sociais e políticas da formação de nível médio: avanços e entraves nas suas modalidades. Educação \& Sociedade, Campinas, v. 32, n. 116, p. 619-638, jul./set. 2011.

15. GUELFI, Wanirley Pedroso. A Sociologia como disciplina escolar no Ensino Secundário brasileiro (1925-1942). 2001. 194f. Dissertação (Mestrado em Educação) - Universidade Federal do Paraná, 2001.

16. IASI, Mauro Luis. Ensaios sobre consciência e emancipação. 2. ed. São Paulo: Expressão Popular, 2011.

17. INSTITUTO NACIONAL DE ESTUDOS E PESQUISAS EDUCACIONAIS ANÍSIO TEIXEIRA. Indicadores educacionais: percentual de docentes com curso superior. Brasília: INEP, 2015a. Disponível em: http://portal.inep.gov.br/indicadores-educacionais. Acesso em 23 jun. 2015. Indicadores educacionais: percentual de docentes por grupo do indicador de adequação da formação do docente. Brasília: INEP, 2015b. Disponível em: http://portal.inep.gov.br/indicadores-educacionais. Acesso em 23 jun. 2015. docente. Brasília: INEP, 2015c. Disponível em: http://portal.inep.gov.br/indicadores-educacionais. Acesso em 23 jun. 2015. Indicadores educacionais: remuneração média dos docentes em exercício na educação básica por escolaridade. Brasília: INEP, 2014. Disponível em: http://portal.inep.gov.br/indicadoreseducacionais. Acesso em 23 jun. 2015.

21. KUENZER, Acacia Zeneida. A formação de professores para o ensino médio: velhos problemas, novos desafios. Educação \& Sociedade, Campinas, v. 32, n. 116, p. 667-688, jul./set. 2011.

22. LIMA, Fabiana Conceição Ferreira de. A sociologia no ensino médio e sua articulação com as concepções de cidadania dos professores. 2012. 130f. Dissertação (Mestrado em Sociologia) Universidade Federal de Pernambuco, Recife, 2012.

23. MACHADO COSTA, Gilvan Luiz. Configurações, limites e perspectivas do Ensino Médio no Brasil: qualidade e valorização dos professores. Práxis Educativa (Brasil), vol. 8, n.1, p. 85-109, jan.-jun. 2013.

24. MARX, Karl. Sobre a questão judaica. São Paulo: Boitempo, 2010a. 

Glosas críticas marginais ao artigo "O rei da Prússia e a reforma social”: de um prussiano. São Paulo: Expressão Popular, 2010b.

26. MELO, Valci. A escolarização média da classe trabalhadora no Brasil: desafios contemporâneos e suas raízes históricas. Trabalho Necessário, Niterói - RJ, n. 26, ano 15, p. 115-141, jan. - jun. 2017.

27. MÉSZÁROS, István. A educação para além do capital. 2. ed. ampliada. São Paulo: Boitempo, 2008 (Tradução de Isa Tavares). Como poderia o Estado fenecer? In: MÉSZÁROS, István. Para além do capital: rumo a uma teoria da transição. 1. ed. rev. - São Paulo: Boitempo, 2011.

29. MEUCCl, Simone. A institucionalização da sociologia no Brasil: os primeiros manuais e cursos. 2000. [s.n]. Dissertação (Mestrado em Sociologia) - Universidade Estadual de Campinas, Campinas (SP), 2000.

MORAES, Amaury César. Ensino de Sociologia: periodização e campanha pela obrigatoriedade. Cadernos Cedes, Campinas, v. 31, n. 85, p. 359-382, 2011. Ciência e ideologia na prática dos professores de sociologia no Ensino Médio: da neutralidade impossível ao engajamento indesejável, ou seria o inverso? Educação \& Realidade, Porto Alegre, v. 39, n. 1, p. 17-38, jan./mar. 2014. GUIMARÃES, Elisabeth da Fonseca. Metodologia de Ensino de Ciências Sociais: relendo as OCEM-Sociologia. In: BRASIL. Sociologia: ensino médio. Brasília: MEC, SEB, 2010. (Coleção Explorando o Ensino; v. 15).

33. MORAES, Luiz Fernando Nunes. Da Sociologia cidadã à cidadania sociológica: as tensões e disputas na construção dos significados de cidadania e do ensino de sociologia, 2009. $240 \mathrm{f}$. Dissertação (Mestrado em Sociologia) - Universidade Federal do Paraná, Paraná, 2009.

34. MOTA, Kelly Cristine Côrrea da Silva. Os lugares da Sociologia na educação escolar de jovens do ensino médio: formação ou exclusão da cidadania e da crítica? 2003. 222 f. Dissertação (Mestrado em Educação) - Universidade do Vale do Rio dos Sinos, São Leopoldo, RS, 2003.

35. OLIVEIRA, Amurabi. Revisitando a história do ensino de Sociologia na Educação Básica. Acta Scientiarum Education, Maringá, v. 35, n. 2, p. 179-189, jul.dez. 2013. 
ORLANDI, Eni Pulcinelli. Análise de discurso: princípios e procedimentos. 2. ed. Campinas: Pontes, 2007.

As formas do silêncio: no movimento dos sentidos. 3. ed. Campinas - SP: Editora da UNICAMP, 1995.

38. PAULO NETTO, José. Posfácio. In: COUTINHO, Carlos Nelson. O estruturalismo e a miséria da razão. 2.ed. São Paulo: Expressão Popular, 2010.

PÊCHEUX, Michel. Semântica e discurso: uma crítica à afirmação do óbvio. 2. ed. Campinas, SP: Editora da UNICAMP, 1995. O discurso: estrutura ou acontecimento. 4. ed. Campinas, SP: Pontes Editores, 2006. .; FUCHS, Catherine. Por uma Análise Automática do Discurso: uma introdução à obra de Michel Pêcheux. 3.ed. Campinas, SP: Editora da UNICAMP, 1997. Papel da memória. In: ACHARD, Pierre et al. Papel da memória. Campinas - SP: Pontes, 1999.

43. PINTO, José Marcelino de Rezende; AMARAL, Nelson Cardoso; CASTRO, Jorge Abrahão de. O financiamento do ensino médio no Brasil: de uma escola boa para poucos à massificação barata da rede pública. Educ. Soc., Campinas, v. 32, n. 116, p. 639-665, jul.-set. 2011.

44. SANTOS, Mário Bispo dos. A Sociologia no ensino médio: o que pensam os professores da rede pública do Distrito Federal. 2002. 170 f. Dissertação (Mestrado em Sociologia) - Instituto de Ciências Sociais da Universidade de Brasília, Brasília, 2002.

45. SARANDY, Flávio Marcos Silva. A Sociologia volta à escola: um estudo dos manuais de Sociologia para o ensino médio no Brasil. 2004. 142 f. Dissertação (Mestrado em Sociologia e Antropologia) - Universidade Federal do Rio de Janeiro, Rio de Janeiro, 2004.

46. SILVA SOBRINHO, Helson Flávio da. O sujeito e a processualidade histórico-social. In: Discurso, Velhice e Classes Sociais. Maceió: Edufal, 2007.

47. TONET, Ivo. Educação contra o capital. Maceió, Edufal, 2007. Método científico: uma abordagem ontológica. São Paulo: Instituto Lukács, 2013. 

jan./jun. 2014.

50. VAISMAN, Ester. A ideologia e sua determinação ontológica. Revista Ensaio, São Paulo, n. 17$18,1989$.

\section{Valci Melo}

Licenciado em Pedagogia pela Universidade Estadual de Alagoas e em Ciências Sociais pela Universidade Federal de Alagoas. É Mestre e Doutorando em Educação pela Universidade Federal de Alagoas, professor de Ensino Fundamental na rede pública municipal de São José da Tapera e professor substituto da Ufal, Campus do Sertão.

\section{Como citar este documento:}

MELO, Valci. O discurso docente acerca do ensino de Sociologia e a identificação ideológica com o atual projeto de sociedade. Reflexão e Ação, Santa Cruz do Sul, v. 27, n. 2, abr. 2019. ISSN 19829949. Disponível em: <https://online.unisc.br/seer/index.php/reflex/article/view/9444>. Acesso em: . doi:https://doi.org/10.17058/rea.v27i2.9444. 